\title{
ПОТРЕБНОСТЬ В АВТОМАТИЗАЦИИ ФИНАНСОВОГО АНАЛИЗА ПРЕДПРИЯТИЯ
}

\author{
Батукаева Анжела Руслановна \\ старший преподаватель кафедры «Бизнес-информатика» \\ Вагапова Марьям Вахаевна \\ ФГБОУ ВО «Чеченский государственный университет \\ имени Ахмата Абдулхамидовича Кадырова»
}

\begin{abstract}
Аннотация: На сегодняшний день разработано много методик проведения финансового анализа предприятия. Во время финансового анализа предприятия могут использоваться самые разнообразные приемы, модели и методы анализа. Их количество и диапазон использования зависят от поставленной цели и определяются задачами анализа в каждой отдельной ситуации. В статье рассматривается потребность в автоматизации финансового анализа предприятия, преимущества и недостатки.
\end{abstract}

Ключевые слова: предприятие, финансовый анализ, автоматизация, финансовое состояние, программное обеспечение.

\section{THE NEED FOR AUTOMATION OF FINANCIAL ANALYSIS OF THE ENTERPRISE}

Batukaeva A.R.
Vagapova M.V.

\begin{abstract}
To date, many methods of conducting financial analysis of the enterprise have been developed. During the financial analysis of an enterprise, a wide variety of techniques, models and methods of analysis can be used. Their number and range of use depend on the goal and are determined by the tasks of analysis in each individual situation. The article discusses the need for automation of financial analysis of the enterprise, advantages and disadvantages.
\end{abstract}

Key words: enterprise, financial analysis, automation, financial condition, software. 
В зависимости от цели анализа исследуются различные показатели деятельности предприятия. $\mathrm{B}$ литературе часто рассматривается необходимость автоматизации внешнего финансового анализа с точки зрения потенциального инвестора при выборе возможного объекта инвестирования. Для автоматизации такого анализа важным фактором является доступ к объективным данным о финансовом состоянии исследуемого объекта [1].

Платформой для автоматизации финансового анализа многие исследователи избирают табличный процессор Microsoft Excel. Хотя такой вариант не идеален, но он упрощает проведение расчетов и значительно экономит время для принятия управленческих решений. Возможными недостатками данного инструмента является то, что его основа использование формул и встроенных функций Microsoft Excel, и, если не установить запрет на изменение соответствующих ячеек, неопытный пользователь может ошибочно изменить алгоритм расчета, сам не зная об этом и получать ложные данные результата анализа [1].

Устранить данный недостаток можно, использовав встроенный язык программирования VBA, для построения алгоритмов расчета показателей и для более удобного представления результатов анализа - например, автоматическое выделение различными цветами показателей, свидетельствующих о стабильном финансовом состоянии предприятия и критических показателей, значения которых отклоняются от нормативных значений. Кроме того, можно использовать более профессиональную платформу для разработки программного приложения, которая бы не зависела от другого программного обеспечения и позволяла бы создавать самостоятельные программные приложения, использование которых не потребует дополнительных расходов.

Предприятия среднего и малого бизнеса используют, преимущественно, информационные системы-конструкторы такие как «1С: Предприятие» и «Акцент», которые настраиваются под нужны и информационные процессы конкретного предприятия [4]. Эти информационные системы позволяют опытным пользователям изменять существующие и создавать новые программные модули с помощью встроенного языка программирования. Именно для таких предприятий актуальна разработка собственного модуля финансового анализа средствами информационной системы. 
Преимуществами такого подхода являются:

- отсутствие необходимости занесения данных для анализа - все необходимые данные уже есть в системе;

- возможность анализа динамики финансового состояния - поскольку все данные хранятся в единой базе данных, можно удобно и быстро отслеживать динамику изменения финансового состояния предприятия;

- отслеживание критических точек финансового состояния использование единой информационной базы позволяет проводить глубокий причинно-следственный анализ финансовых показателей и выявлять негативные тенденции того или иного показателя на ранних стадиях и предотвращать критическим ситуациям;

- возможность осуществлять прогнозирование финансового состояния предприятия с учетом тенденций предыдущих периодов и текущего промежуточного состояния, что позволит предотвратить возможные кризисные ситуации или на всю мощность, использовать имеющийся финансовый потенциал.

Исходные данные для автоматизированного финансового анализа содержатся в стандартных формах бухгалтерской отчетности. Для проведения более детального анализа используется информация о структуре затрат и условиях привлечения кредитов. Таким образом, большинство подобного рода программных продуктов, в качестве исходной информации используют следующие формы отчетности [4]:

- Бухгалтерский баланс;

- Отчет о финансовых результатах;

- Отчет о движении денежных средств;

- Приложения к бухгалтерскому балансу.

- Автоматизированные системы финансового анализа могут являться:

- автономными программами;

- интегрированными в комплексное ПО для обработки учетной информации.

На рынке программного обеспечения широко представлены продукты, предназначенные для автоматизированного анализа финансово-хозяйственной деятельности. Финансовое состояние описывается с помощью показателей и коэффициентов, а также предоставляют результаты в виде графиков и диаграмм [4]. Автоматизированные системы представляют информацию о 
структуре баланса, величинах показателей ликвидности, финансовой устойчивости, прибыльности, оборачиваемости, рентабельности, движении денежных средств.

Преимущества автономных программ: понятность, не нужно приобретать дополнительное программное обеспечение. Минус данных программ: чаще всего необходим ввод данных.

Плюс интегрированных программ: рассчитывается больше показателей.

Недостатки интегрированных программ:

- сложность, не всегда понятно, как рассчитывался тот или иной показатель;

- больше подходят для крупных предприятий;

- жестко привязаны к форматам данных программ того же производителя, но ряд из них позволяет загружать данные и из внешних источников.

Подытоживая вышесказанное, отметим, что важным условием сохранения финансовой устойчивости и стабильности организации являются периодический мониторинг финансового положения и его показателей, оперативное выявление негативных отклонений и принятия взвешенных управленческих решений для их ликвидации. Для этого необходим определенный инструмент, позволяющий проводить финансовый анализ. Этим инструментом может быть, как отдельное программное приложение, так и комплексное решение для автоматизации всей деятельности предприятия, в том числе и финансового учета. Поскольку методики проведения финансового анализа для предприятий одинаковы, а входная информация регламентирована, то целесообразна разработка программных модулей финансового анализа для распространенных информационных систем учета как для собственного использования, так и в качестве коммерческого программного продукт, который может принести дополнительную финансовую выгоду. 


\section{Список литературы}

1. Жилкина А.Н. Финансовый анализ: учебник и практикум для вузов / А.Н. Жилкина. - М.: Издательство Юрайт, 2020. - 285 с.

2. Садыр Ж. Основы финансового анализа субъектов малого и среднего бизнеса / Ж. Садыр. - М.: Издательство альпина, 2020.

3. Мандражи 3.Р. Концептуальные основы автоматизации финансового анализа в условиях глобализации // Ученые записки Крымского инженерно-педагогического университета. 2020. - № 2 (68). - С. 141-145.

4. Минина Т.И. Проблемы автоматизации финансового анализа // Хроноэкономика. 2020. - № 7 (28). - С. 20-23.

(C) Вагапова М.В., Батукаева А.Р., 2021 